International Review of Research in Open and Distributed Learning Volume 18, Number 3

May - 2017

\title{
Adaptive or Transactional Leadership in Current Higher Education: A Brief Comparison
}

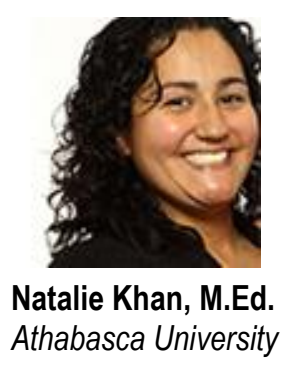

\begin{abstract}
Higher education institutions operate in a complex environment that includes influence from external factors, new technologies for teaching and learning, globalization, and changing student demographics to name a few. Maneuvering such complexity and change requires a leadership strategy that is flexible and supportive. This paper reviews two leadership theories in reference to this need: adaptive leadership theory and transactional leadership theory. Three conceptual categories of environmental readiness, leadership complexity, and followers' motivation are used as points of comparison for each theory. A recommendation is made for leadership strategy in higher education institutions based on this comparison.
\end{abstract}

Keywords: higher education, reform, adaptive leadership, transactional leadership, motivation

\section{Introduction}

Higher education is experiencing demands for change due to pressure from many factors, such as the need for greater access through open and distributed learning, new technology, funding decreases, student demographics, and globalization. (Duderstat, 2009). In fact,

today's technological revolution, with its order of magnitude advances that have left little of common life unchanged, presents an open challenge to the University to once again 'reinvent' itself. Indeed, it could be argued that the pressure for change placed on the University today is greater than any it has faced in any previous historical epoch. (Amirault \& Visser, 2009, p. 64) 
Because of this, higher education institutions need to adopt a leadership approach that will allow them to be flexible and responsive to change. This can be aided by support from a leadership theory that will guide them in leading others and making decisions.

Leading with a plan for dealing with change, then, is a requirement. An adaptive leadership approach takes a holistic view of leadership by focusing on both leader-follower relationships and any potential external issues. Adaptive leadership allows institutions to properly plan for change and consider many factors affecting the complex nature of the leadership relationship. To explicate this assertion, we evaluate adaptive leadership in reference to a commonly used, traditional leadership theory; transactional leadership. To begin the evaluation process, a description of both adaptive and transactional leadership is provided. Then a comparison of both theories, based on three conceptual categories of environmental readiness, leadership complexity, and followers' motivation is provided. A recommendation is made outlining the most effective leadership theory for education institutions to implement based on the environment in which they operate.

\section{Leadership Theories Defined}

\section{Adaptive Leadership}

Adaptive leaders do not just make changes, they carefully recognize potential changes in the external environment and consider the best path that will positively affect the organization. According to Yukl and Mahsud (2010) "flexible and adaptive leadership involves changing behavior in appropriate ways as the situation changes" (p.1). Adaptive leaders look not only at the leader-follower relationship, but also consider external factors in the environment within which leaders and followers operate (Glover, Rainwater, Jones, \& Friedman, 2002).

Adaptive leadership allows leaders to mobilize "people to tackle tough challenges and thrive" (Heifetz, Linsky, \& Grashow, 2009, p. 14). Adaptive leaders are adept in knowing what the problems are, defining them carefully, and finding appropriate solutions. Critics of adaptive leadership state that even though this theory is effective for organizations planning for change, many organizations are actually resistant to an adaptive leadership approach (Yukl \& Mahsud, 2010). This is because adaptive leadership challenges beliefs, values, and norms, which may lead individuals to resist the ideas and changes that emerge from an adaptive leadership approach (Yukl, 2010). However, adaptive leadership considers all factors that affect an organization, by properly planning for a changing world, which makes an adaptive leadership approach useful and valid in dynamic societies.

\section{Transactional Leadership}

Transactional leadership theory is widely used in educational institutions. According to Avolioi, Walumbwa, and Weber (2009), transactional leadership is "largely based on the exchange of rewards contingent on performance" (p.427). Transactional leadership focuses on the leader-follower relationship. It is commonly used in education in the relationship between instructors and students. Students are required to complete projects, assignment, or tests and if they perform well, they will be awarded good 
marks or the ability to pass. This process may be an easy extension to the performance requirements in education institutions outside the classroom.

Now that these leadership theories have been defined, both leadership theories are discussed based on environmental readiness.

\section{Environmental Readiness}

Cleveland-Innes (2012) states that "change in education to accommodate broader societal change embodies new ways of thinking about access to education, economic issues, accountability, technology in the teaching-learning process, and, most importantly, leadership” (p. 1). It is important that educational institutions have a practical and useful leadership strategy to help navigate through environmental changes. Adaptive leadership supports educational institutions to navigate through change because it does not rely on previous experience alone to address problems, but rather looks at current challenges to determine resolution. This is effective because organizations will avoid taking the same actions previously made; hence they will be more open to adjusting as the situation requires. Adaptive leaders recognize the best solution to address problems based on current realities rather than actions based on the past.

In terms of environmental readiness, transactional leadership is less likely to consider potential situational or environmental changes in an organization because it focuses on leader-follower interactions and not external factors (Avolioi et al., 2009). Given this, where external factors are not considered, there is more of a chance that decisions will be made without all factors being considered, leading to poor decision making.

In the next section each leadership theory's ability to handle complex situations will be reviewed.

\section{Handling Complex Situations}

The leadership process itself has many competing values and, therefore, is more complex and difficult than traditionally thought (Yukl \& Mahsud, 2010). Educational institutions are also complex organizations that have many, even competing, internal and external factors that need to be considered when leading and making decisions. Education institutions need to choose a leadership strategy that takes into account the difficult nature of leadership and individual, current, and organizational complexity.

Adaptive leadership can be implemented in complex situations where the leader-follower relationship is attended to, but so are all environmental, cultural, and societal factors that will affect leaders and followers (Glover, Rainwater, Jones, \& Friedman, 2002). An adaptive leadership approach will help facilitate organizations to adapt to potential changes by encouraging collective learning and collaboration by the organizations members (Yukl \& Mahsud, 2010). Adaptive leaders focus on working with all members to elicit change for the greater good of an organization. As such, adaptive leadership theory will help education intuitions achieve their vision through agreed-upon ideas and direction. 
Transactional leadership rest on behaviorist views of human activity. Leaders are those in positions of power, providing rewards and punishments (carrots and sticks) as part of leader-follower relations. This supports adherence to policy, regulations, and the status quo. However, this type of engagement limits the opportunity "to capture the complexity of leadership processes in modern organizations" (Yukl \& Mahsud, 2010, p.83). Where there is failure to consider the bigger picture, incomplete planning results. According to Benjamin (2016), transactional leaders have an "over-reliance on a single approach, and unwillingness to discuss, or even consider, the ideas of others, which limits a leader's creativity and his ability to adjust if things go wrong" (Benjamin, 2016, p.1). Without flexibility and willingness to change strategies as internal or external issues arise, transactional leadership is seen as less effective for complex educational organizations.

\section{Leadership Theories Capabilities to Motivate}

Motivation plays an important role in education; for the student, the faculty, and the administrators. Motivating students to achieve success is an activity for all faculty, creating an awareness about motivation among the rank and file that may not be present in other types of organizations. Adaptive leadership creates follower motivation by taking into account individual needs and goals. It goes beyond instant rewards, helps develop followers' abilities, and provides challenges. Yukl and Mahsud (2010) indicate that adaptive leaders will motivate followers by: understanding their values, recognizing if they are struggling and need assistance, delegating responsibilities, and including followers in the analysis and decision making process. In a case study by Lewis (2014), an owner used adaptive leadership successfully to help an organization navigate around external issues. In this case, the leader chose adaptive leadership to help keep performance up and employees motivated because the previous use of a reward incentive was unsuccessful.

Transactional leadership provides followers a reward for achieving a set target. However, transactional leadership is only motivating on a base level and fails to motivate individuals beyond the set goal; nor does it advance individual development (Transactional Leadership Advantages and Disadvantages, 2016). Transactional leaders tend not to recognize or praise individuals' contributions beyond the goal that was set for the initial incentive, nor do they give an incentive for going beyond the achieved target (Benjamin, 2016). Followers may become demotivated or may not strive for higher achievements because of the lack of praise for greater achievement by the transactional leader, which would be a disadvantage for educational institutions. Transactional leaders focus solely on the reward and benefit systems and fail to address or change their approaches if followers be unable to achieve their targets (Benjamin, 2016).

It is now important to consider how these theories discussed may apply in educational institutions in the $21^{\text {st }}$ century.

\section{Recommendations}

The three conceptual categories discussed above provide a foundation for comparison of adaptive and transactional leadership in reference to contemporary educational institutions. Transactional leadership is 
extremely effective in motivating followers to achieve goals. However, it has been questioned as an effective way to motivate followers beyond the initial goals set for them. Additionally, transactional leadership does not consider external or situational issues but focuses on leader-follower relationships. This is a necessary but insufficient set of actions for shaping contemporary higher education.

As identified above, adaptive leadership is effective in specific situations where change has occurred; it may not be effective in managing the status quo. However, it can be argued that in today's society, change is ubiquitous and educational institutions need strategies to respond to the demands of such change. An adaptive leadership approach allows institutions to consider situations uniquely and select actions based on what is needed currently rather than on past traditions. For these reasons, an adaptive leadership approach may be more valuable as a leadership approach in current educational institutions.

\section{Conclusion}

After comparing adaptive and transactional leadership, we submit that neither leadership theory can address all required actions in contemporary education institutions, but that adaptive leadership is flexible, takes into account current complexities, and is highly motivating for followers. Adaptive leadership takes a holistic view of leadership by focusing on both the leader-follower relationship and environmental issues. For these reasons, adaptive leadership strategy is more a more appropriate choice, when choosing between these two theories, for educational institutions to employ. The flexibility and orientation toward change offered by adaptive leadership theory provides strategy to respond to demands for change in reference to the need for greater access through open and distributed learning, new technology, funding decreases, student demographics, and globalization.

\section{References}

Amirault, R. J., \& Visser, Y. L. (2009). The university in periods of technological change: A historically grounded perspective. Journal of Computing in Higher Education, 21(1), 62-79.

Avolioi, B., Walumbwa, F., \& Weber, T. J. (2009). Leadership: Current theories, research, and future directions. Management Department Faculty Publications, 37. Retrieved from http://digitalcommons.unl.edu/managementfacpub/37

Benjamin, T. (2016). Transactional leadership limitations [Blog post]. Retrieved from http://smallbusiness.chron.com/transactional-leadership-limitations-35903.html

Cleveland-Innes, M. (2012). Editorial: Who needs leadership? Social problems, change, and education futures. The International Review of Research in Open and Distance Learning, 13(2), 232-235. Retrieved from http://www.irrodl.org/index.php/irrodl/article/view/1226/2174 
Duderstadt, J. J. (2009). A university for the 21s century. Ann Arbor, Michigan: University of Michigan Press.

Glover, J., Rainwater, K., Jones, G., \& Friedman, H. (2002). Adaptive leadership: Four principles for being adaptive (Part 2). Organization Development Journal, 2O(2), 18-38.

Heifetz, R. A., Linsky, M., \& Grashow, A. (2009). The practice of adaptive leadership: Tools and tactics for changing your organization and the world. Cambridge, MA: Harvard Business Press.

Lewis, S. (2014). Positive adaptive leadership and key principles of practice in a time of uncertainty. $A I$ Practitioner, 16(1), 20-24. doi:10.12781/978-1-907549-18-2-3

Transactional Leadership Advantages and Disadvantages. (2016). Retrieved from http://www.adviseamerica.com/transactional-leadership-advantages-and-disadvantages/

Yukl, G. (2010). Leadership in organizations (7th ed.). Upper Saddle River, NJ: Prentice Hall.

Yukl, G., \& Mahsud, R. (2010). Why flexible and adaptive leadership is essential. Consulting Psychology Journal: Research and Practice, 62, 81- 93. 